\title{
ORIGINAL ARTICLE \\ It's a bear market: evolutionary and ecological effects of predation on two wild sockeye salmon populations
}

\author{
JE Lin ${ }^{1}$, J Hard ${ }^{2}$, KA Naish ${ }^{1}$, D Peterson ${ }^{1,3}$, R Hilborn ${ }^{1}$ and L Hauser ${ }^{1}$ \\ Predation can affect both phenotypic variation and population productivity in the wild, but quantifying evolutionary and \\ demographic effects of predation in natural environments is challenging. The aim of this study was to estimate selection \\ differentials and coefficients associated with brown bear (Ursus arctos) predation in wild sockeye salmon (Oncorhynchus nerka) \\ populations spawning in pristine habitat that is often subject to intense predation pressure. Using reconstructed genetic \\ pedigrees, individual reproductive success (RS) was estimated in two sockeye salmon populations for two consecutive brood \\ years with very different predation intensities across brood years. Phenotypic data on individual adult body length, body depth, \\ stream entry timing and reproductive lifespan were used to calculate selection coefficients based on RS, and genetic variance \\ components were estimated using animal models. Bears consistently killed larger and more recently arrived adults, although \\ selection differentials were small. In both populations, mean RS was higher in the brood year experiencing lower predation \\ intensity. Selection coefficients were similar across brood years with different levels of predation, often indicating stabilizing \\ selection on reproductive lifespan as well as directional selection for longer reproductive lifespan. Despite these selection \\ pressures, genetic covariation of morphology, phenology and lifespan appears to have maintained variation in spawner body size \\ and stream entry timing in both populations. Our results therefore suggest considerable demographic but limited evolutionary \\ effects of bear predation in the two study populations.
}

Heredity (2016) 116, 447-457; doi:10.1038/hdy.2016.3; published online 10 February 2016

\section{INTRODUCTION}

As an agent of natural selection, predation can have both ecological (demographic) and evolutionary effects. Predation can regulate sizes of natural populations (Hixon and Carr, 1997) and determine foodweb and ecosystem dynamics (Mills et al., 1993). Evolutionarily, predation can influence phenotypic divergence within species (Vamosi, 2005), affecting life history, morphology and other traits (Reznick and Endler, 1982; Nosil and Crespi, 2006). Predators may show a preference for killing individuals with specific phenotypes, a phenomenon termed 'selectivity.' When predation pressure is high, selectivity might result in adaptations that reduce predation risk and increase survival and opportunity for reproduction (Magnhagen, 1991).

Selective effects of predation have recently received increased attention because of the potential for anthropogenic selection in many exploited species, which may lead to phenotypes less adapted to the natural environment (Law, 2007; Hard et al., 2008). Despite these interests, the selection coefficients and demographic and evolutionary effects associated with natural predation are rarely quantified. Even in well-established model systems, such as Trinidadian guppies (Poecilia reticulata; Reznick et al., 1996) and stick insects (Timema cristinae; Nosil and Crespi, 2006), there are few quantitative estimates of predation intensity and selectivity, which are critical for determining mechanistic links between predation and evolution in wild populations.

Most existing estimates of selectivity in wild populations are based on traits correlated with fitness rather than fitness (that is, lifetime reproductive success (RS)) itself. In contrast, pedigree studies allow direct estimation of individual lifetime RS and can, in connection with phenotypic data, provide powerful insights into the causes and effects of selection in wild populations (Coltman et al., 2003; Seamons et al., 2007; Pemberton, 2008). Quantifying individual RS may also provide insights into the demographic effects of predation. However, predation interacts with density-dependent processes (Hixon and Carr, 1997) and sexual selection (Reznick et al., 1996), and so selective mortality by predation may not always result in reduced RS.

Wild Pacific salmon (Oncorhynchus spp.) are an attractive candidate for studying the effects of predation because predators can have substantial effects on phenotypic traits as well as demography, and because pedigree reconstruction is feasible in some populations. Prior studies of the semelparous sockeye salmon (O. nerka) in Alaska have shown that brown bears (Ursus arctos) preferentially kill large adults (Quinn and Kinnison, 1999; Cunningham et al., 2013), perhaps because large fish offer more caloric energy per capture effort and are easier to catch (Gende et al., 2004). On the other hand, sexual selection might favor larger individuals of both sexes

${ }^{1}$ School of Aquatic and Fishery Sciences, University of Washington, Seattle, WA, USA and ${ }^{2}$ Conservation Biology Division, Northwest Fisheries Science Center, National Marine Fisheries Service, NOAA, Seattle, WA, USA

Correspondence: Dr JE Lin, Current address: Ocean Outcomes, 421 SW Sixth Avenue, Ste 1400, Portland, OR 97204, USA.

E-mail: jocelynlin98@gmail.com

${ }^{3}$ Current address: Graduate Program in Organismic and Evolutionary Biology, University of Massachusetts Amherst, 319 Morrill S., 611 N. Pleasant Street, Amherst, MA 01003, USA

Received 13 August 2015; revised 6 December 2015; accepted 18 December 2015; published online 10 February 2016 
(Quinn et al., 2001b), and larger females generally have higher fecundity (Dickerson et al., 2002). Environmental factors such as stream size and flow regimes may also affect body shape, with salmon spawning in smaller, shallower streams tending to have smaller bodies (Hendry and Quinn, 1997). Such opposing selection pressures may contribute to the morphological differences observed among stream populations, with deeper streams, where bear predation is less intense and flows are greater, often supporting deeper-bodied fish (Quinn et al., 2001b; Carlson et al., 2009). Bear predation may affect individual fitness by shortening reproductive lifespan as well as reducing body size (Carlson et al., 2009), especially because bears tend to target salmon that have just arrived in the breeding area rather than postspawning fish nearing senescence (Carlson et al., 2007). In addition to reducing spawning opportunity, a shorter reproductive lifespan can limit redd (nest) defense in females, which affects egg survival because undefended redds may be disturbed and superimposed upon by females arriving later in the season (Hendry et al., 2004).

In this paper, we quantify the demographic and evolutionary effects of bear predation on sockeye salmon populations by estimating and comparing individual RS and selection coefficients between two consecutive brood years that experienced very different predation rates. To accomplish this we linked four distinct approaches. First, we estimated demographic effects of bear predation by comparing the number of salmon recruits-per-spawner (RPS) between brood years. Second, we estimated selectivity of predation by bears for salmon with specific morphological, phenological and reproductive phenotypes. Third, we quantified natural selection on these traits by estimating individual RS from reconstructed molecular pedigrees and comparing selection coefficients between brood years to determine if differences in predation rates were associated with different modes and intensities of selection. Finally, we used animal models to estimate genetic variance-covariance $(G)$ matrices for the phenotypes under selection, thereby characterizing opportunities for selection and adaptation of these sockeye salmon populations under bear predation.

\section{MATERIALS AND METHODS}

\section{Sampling}

A Creek and C Creek are two small tributaries to Little Togiak Lake in the Wood River Lakes system in southwestern Alaska (Figure 1). These streams are free from anthropogenic disturbances in the freshwater environment, such as habitat alteration or hatchery supplementation, and they are suitable replicates because they are in close geographic proximity and have the following

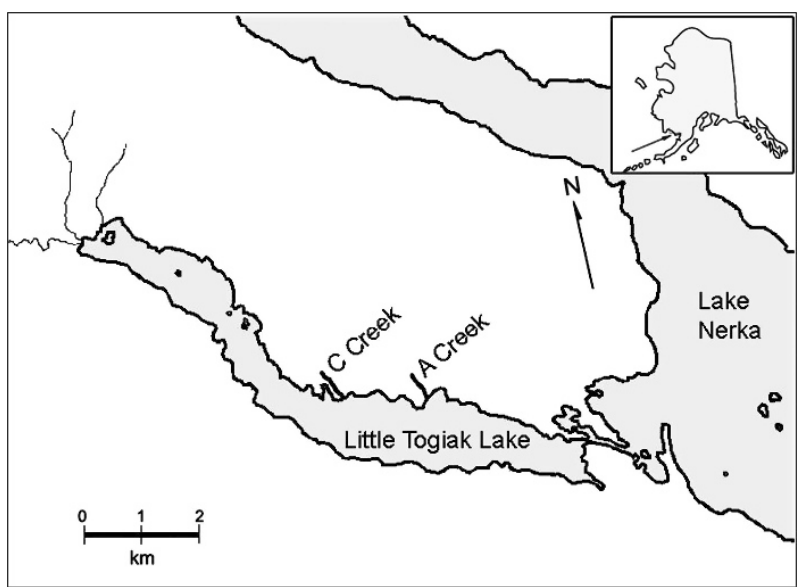

Figure 1 Map of the study sites (A Creek and C Creek) in southwestern Alaska. Arrow in inset figure points to the location of the Wood River Lakes system. ecological similarities. Both streams are small and shallow; A and C creeks have $\sim 0.37$ and $\sim 0.44 \mathrm{~km}$ of salmon spawning habitat, respectively, and wetted stream depths average about $10-14 \mathrm{~cm}$ during the spawning season. Several hundred adult sockeye salmon return to each stream annually, spawning from late July until late August (Lin et al., 2008). Brown bears are the primary natural predators of the spawning adult salmon. The sockeye salmon are subjected to commercial fishing at sea, but fishery selection on fish body size (Kendall and Quinn, 2009, 2013) likely affects both populations similarly, as salmon from these two populations have comparable body sizes and return timing (Lin et al., 2008).

Because of the shallow wetted depths, salmon spawning in these streams are very vulnerable to bear predation. C Creek has some undercut banks where fish can hide, but it is not uncommon for bears to kill more than $50 \%$ of the salmon present in these streams on a given day based on the daily stream surveys we conducted for this study during the 2004-2005 and 2008-2010 spawning seasons (described in the following paragraph). However, there can be substantial annual variation in prevalence of bear predation. Bears killed a high fraction of fish in both streams in 2004, but bear mortality was rare in 2005.

The A and C creek sockeye salmon populations were sampled exhaustively during the summers of 2004 and 2005 (parents; 2004 and 2005 were the brood years we analyzed) and 2008-2010 (returning adult offspring). Each year, field crews visually monitored both streams starting around 25 July, typically several days before entry of the first salmon. After fish started entering, the entire length of each stream was surveyed daily until no live fish remained in the streams ( $\sim 4$ weeks). During the surveys, all untagged individuals were captured, measured, marked with a uniquely numbered plastic disc tag under the dorsal fin, and sampled for fin tissue that was preserved in $95 \%$ ethanol for genetic analysis. In addition, adipose fins were removed from tagged individuals to ensure that they could be identified as previously tagged even if the disc tag was lost. The dorso-ventral body depth from the anterior insertion of the dorsal fin to the belly and the body length from the mid-eye to the end of the hypural bone were measured to the nearest millimeter, and standardized body depths were also calculated following Ihssen et al. (1981) to obtain a measure of body depth adjusted for body length. Deeper-bodied fish move less efficiently and are more visually apparent in shallow streams, which makes them more susceptible to predators than fish with shallower body depths (Quinn et al., 2001a). When a salmon carcass was found, the tag and mode of death (bear-kill or senescence) were recorded. Mode of death was recorded for tagged individuals only when the tag could be visually confirmed. Fin clips were taken from untagged carcasses for genetic analysis, and if the body was intact, measurements of body length and depth were taken as well. To ensure that we did not resample individuals whose tags had been removed or consumed by bears, we checked carcasses for the presence of an intact adipose fin. In addition, we could have easily identified any resampled individuals using the genetic data collected for parentage analysis. All carcasses were removed from the streams to prevent resampling, and otoliths were collected for age determination from all tagged and untagged carcasses that could be recovered ( $\sim 56 \%$ of the sampled fish). We may have missed capturing some individuals during our surveys, but prior work suggested that sampling coverage was over 90\% (Hauser et al., 2011).

The tag observations provided empirical data for several life-history and behavioral parameters. For each individual, we recorded date of stream entry (date first seen in the creek, assumed to coincide with initiation of reproductive opportunity) and reproductive lifespan (number of days a fish was observed alive in the stream; hereafter also referred to as lifespan). We did not estimate lifespan as the days elapsed between the first and last observation of an individual in the stream, because some fish left the stream for the lake and subsequently re-entered, so days elapsed might not accurately reflect total time spent in the spawning stream (Bentley et al., 2014). A and C creeks are separated by $<2 \mathrm{~km}$ (Figure 1), but only $1.7 \%$ of individuals were observed in both streams. We initially assumed that an individual spawned in the stream where it was observed more frequently, and fish that were observed with the same frequency in both streams had no specific spawning location designated. However, one male and one female with ambiguous spawning locations were later found to have produced offspring that returned to C Creek, and thus we retroactively assigned them both to the $\mathrm{C}$ Creek population. The mean number 
of live fish present in the streams each day was used as an indicator of population density.

\section{Demographic analysis}

We performed several comparative analyses to better understand variation in bear predation across brood years and populations, and to assess selectivity of bears for killing salmon with certain phenotypes. To determine whether fish were more likely to be killed by bears in 2004 than in 2005, we compared proportions of bear-killed fish between brood years within each stream population using Fisher's exact test. We also used Fisher's exact test to determine if bears preferred killing fish of either sex. We used separate, univariate analyses of variance to test for differences in mean reproductive lifespan and mean number of live fish per day between brood years.

Differences between brood years in recruitment may be due to differences in bear selection, or difference in ocean conditions. To account for effects of ocean conditions on population productivity for the 2004 and 2005 brood years, we estimated productivity for those same brood years for four other Wood River system stream populations (Eagle Creek, Elva Creek, Hansen Creek, Mission Creek) that utilize the same marine habitat as the $\mathrm{A}$ and $\mathrm{C}$ creek populations (Myers et al., 1996) but that did not experience comparable discrepancies in predation rates between 2004 and 2005. These specific populations were chosen because, like the $\mathrm{A}$ and $\mathrm{C}$ creek populations, they have a high proportion of spawning adults that are 4 years old (always above 50\% for the years under consideration). However, because pedigrees were not reconstructed for these other populations, we estimated an alternative measure of productivity termed adult RPS, which was defined as:

$$
\text { RPS }=N_{t+1} / N_{t}
$$

where $N_{t}$ is the number of spawning adults at time $t$, and $N_{t+1}$ is the number of spawning adults at the next time step. We assumed a time step of 4 years (approximately one generation), calculating $\mathrm{RPS}_{2004}$ as $N_{2008} / N_{2004}$ and $\mathrm{RPS}_{2005}$ as $N_{2009} / N_{2005}$. This RS measure is imperfect but appropriate for comparing productivity across populations that had pedigrees and those that did not. In addition, we examined fishery selectivity data for sockeye salmon in the Nushagak district in 2008 and 2009, to determine whether variable fishing pressure contributed to productivity differences between years. Selectivity was estimated as the difference between fishery catches and escapements in observed age composition from each stock, standardized to a mean of one (Cunningham et al., 2012).

\section{Selectivity analysis}

To determine if bears preferred killing fish with specific phenotypic traits, weighted selection differentials for each population were calculated for the entire season. Selection differentials were calculated as the mean trait value of surviving individuals minus the mean trait value for all individuals present that day, weighted by the harmonic mean number of bear-killed and surviving fish. In addition, we calculated standardized selection differentials by dividing absolute differentials by the standard deviation of all fish on the respective day (Cunningham et al., 2013). Individuals that senesced were not included in the analysis.

\section{Molecular genetic analysis}

Genetic data were collected to reconstruct pedigrees for the 2004 and 2005 brood years in A and C creeks. Parentage was determined using 11 highly polymorphic DNA microsatellite markers: One100, One102, One103, One106, One108, One109, One111, One114, One115 (Olsen et al., 2000), One110c (see Lin et al., 2008) and Ots103 (Beacham et al., 1998). Estimated genotyping error rates for these microsatellite markers were low, with a mean allele dropout error rate of 0.006 and a mean false allele error rate of 0.017 (Hauser et al., 2011). DNA was extracted from fin tissue using DNeasy kits, and markers were amplified via PCR using Multiplex PCR kits (QIAGEN, Valencia, CA, USA). The microsatellite markers were organized into three electrophoresis panels (panel 1: One100, One103, One106, One110c, Ots103; panel 2: One109, One111, One112, One114; panel 3: One102, One108, One115). Each PCR consisted of $2 \mu \mathrm{l}$ extracted DNA, 1x QIAGEN Multiplex PCR Master Mix, $0.2 \mu \mathrm{M}$ of each primer and water to make up a total $10 \mu \mathrm{l}$ reaction volume. For panels 1 and 2, each reaction underwent an initial polymerase activation and DNA denaturation at $95{ }^{\circ} \mathrm{C}(15 \mathrm{~min})$, followed by 31 cycles of denaturation at $94{ }^{\circ} \mathrm{C}(30 \mathrm{~s})$, annealing at $58.5^{\circ} \mathrm{C}(90 \mathrm{~s})$ and extension at $72{ }^{\circ} \mathrm{C}(60 \mathrm{~s})$. Finally, the reactions were held at $60^{\circ} \mathrm{C}(30 \mathrm{~min})$ and then at $4^{\circ} \mathrm{C}(5 \mathrm{~min})$. Panel 3 reactions followed the same protocol except that the annealing temperature was $60^{\circ} \mathrm{C}$. All forward primers were labeled with fluorescent dye, and the labeled PCR fragments were size-separated on a MegaBACE 1000 (GE Healthcare, Pittsburgh, PA, USA) sequencer with an appropriate size standard. Allele fragment size estimates were obtained using Genetic Profiler genotyping software (GE Healthcare).

The microsatellite data were tested for deviations from Hardy-Weinberg and linkage equilibrium using GENEPOP version 4.0.10 (Raymond and Rousset, 1995). Effective population sizes $\left(N_{\mathrm{e}}\right)$ for each sampling year were estimated in LDNE (Waples and Do, 2008) using only alleles with frequency $\geqslant 0.02$. MICROCHECKER (van Oosterhout et al., 2004) was used to check for evidence of stuttering, large allele dropout and null alleles. The program CERvus 3.0 (Kalinowski et al., 2007) was used to calculate locus-specific exclusion probabilities for assigning parents to offspring.

\section{Pedigree reconstruction}

Data for potential parents (adults in 2004, 2005) and offspring (adults in 2008, 2009 , 2010) were used in Colony (Jones and Wang, 2010) to determine parentage via maximum likelihood. COLONY infers parentage and sibships jointly using the likelihood of the full pedigree, a more efficient and accurate approach than comparing likelihoods of individual pairwise relationships (Walling et al., 2010). Locus-specific error rates from Hauser et al. (2011) were used in the COLONY analysis. Data from both populations were analyzed together to increase candidate parent and offspring pools and to check for assignment errors where the mother and father of a parent pair were not observed in the same stream. Because only potential offspring sampled from 2008 to 2010 were analyzed, 3-year-old offspring of 2004 candidate parents and 6-year-old offspring of 2005 parents were not included in the pedigree. However, these age groups are very rare in these populations; only four age- 3 otoliths and one age- 6 otolith were found among 2431 samples (see proportions in Table 1).

Seventeen candidate parents that lacked sex information were included in both candidate mother and father files for COLONY. The probability of sampling the true parent was conservatively set to 0.5 for both mothers and fathers, even though actual sampling probabilities were likely higher than 0.5 . COLONY calculates probability estimates for maternal and paternal assignments, and only assignments with probabilities of 0.95 or higher were accepted, following Hauser et al. (2011). Differences in mean RS between populations and brood years were tested for using Mann-Whitney-Wilcoxon tests.

\section{Estimation of selection coefficients based on RS}

We assessed modes and directions of natural selection on the A and C creek populations by estimating selection coefficients, following the procedure developed by Lande and Arnold (1983). Selection coefficients were estimated using zero-inflated negative binomial (ZINB) multiple linear regression models with individual lifetime RS as the fitness metric (response variable). RS was defined as the number of returning adult offspring per spawner and was based on the $\mathrm{A}$ and $\mathrm{C}$ creek pedigree data. We selected ZINB models after comparing different model types (ZINB, ordinary least squares, negative binomial) using Akaike Information Criterion (AIC) values. AIC values corrected for finite sample sizes (AICc) were estimated as well, but they were essentially identical to AIC values. The ZINB models had the lowest AIC values and appeared the most suitable for the dependent data (RS), which were zero-inflated and overdispersed.

Regressions were run separately for each population, brood year and sex so that patterns in selection coefficients could be compared across groups. We ran two regression models on each group. The first model included the following predictor variables: fish body length, standardized body depth, date of first stream entry, reproductive lifespan and death fate. The second model included the same predictor variables, except death fate, for the purpose of increasing sample sizes; $~ 35 \%$ of individuals had no recorded death fate because their carcasses were never recovered. Continuous variables were standardized to a mean of 0 and standard deviation of 1 within the data set used for each regression, that is, for each sex-brood year-population grouping. Variance 
Table 1 Summary of sockeye salmon data, separated by population, sex and sampling year

\begin{tabular}{|c|c|c|c|c|c|c|c|c|c|c|c|c|c|c|c|c|}
\hline Ck & Sex & Year & $\mathrm{N}$ & $B k$ & Sen & Age 3 & Age 4 & Age 5 & Age 6 & Length & Depth & Std depth & Date & Lifespan & $P D$ & $R S$ \\
\hline \multirow{3}{*}{ A } & \multirow{3}{*}{$\mathrm{F}$} & 2005 & 290 & 0.04 & 0.61 & 0.00 & 0.67 & 0.33 & 0.00 & $449.8(30.4)$ & 109.5 (10.6) & $117.1(13.4)$ & 9 Aug (6.6) & $8.3(5.0)$ & $86(51)$ & $2.5(3.3$ \\
\hline & & 2009 & 442 & 0.62 & 0.02 & 0.00 & 0.95 & 0.05 & 0.00 & $424.6(19.6)$ & $180.3(12.0)$ & $109.1(7.9)$ & 12 Aug (7.9) & $2.6(1.5)$ & & \\
\hline & & 2010 & 269 & 0.77 & 0.00 & 0.00 & 0.81 & 0.19 & 0.00 & $422.5(25.1)$ & $107.9(10.1)$ & $114.8(7.4)$ & 6 Aug (4.6) & $1.3(0.5)$ & & \\
\hline \multirow[t]{3}{*}{ A } & \multirow[t]{3}{*}{$M$} & 2004 & 161 & 0.76 & 0.01 & 0.00 & 1.00 & 0.00 & 0.00 & $411.8(26.1)$ & 119.5 (11.5) & $133.8(9.5)$ & 8 Aug (6.0) & $2.4(1.3)$ & $9(12)$ & $1.5(2.7$ \\
\hline & & 2009 & 202 & 0.64 & 0.00 & 0.01 & 0.87 & 0.12 & 0.00 & $436.8(32.2)$ & $134.7(14.6)$ & $139.6(10.5)$ & 8 Aug (6.4) & $3.3(1.7)$ & & \\
\hline & & 2010 & 161 & 0.77 & 0.00 & 0.00 & 0.74 & 0.26 & 0.00 & $436.1(36.5)$ & $129.2(19)$ & $134.1(10.4)$ & 5 Aug (5.4) & $1.3(0.5)$ & & \\
\hline \multirow[t]{4}{*}{ C } & \multirow[t]{4}{*}{$\mathrm{F}$} & 2004 & 306 & 0.51 & 0.21 & 0.00 & 0.95 & 0.05 & 0.00 & $414.2(19.9)$ & $105.9(8.0)$ & $115.1(6.8)$ & 5 Aug (5.2) & $6.0(4.0)$ & $56(53)$ & $1.7(4.1$ \\
\hline & & 2005 & 176 & 0.07 & 0.53 & 0.00 & 0.57 & 0.43 & 0.00 & $448.5(29.3)$ & $113.1(12.7)$ & $113.4(9.7)$ & 7 Aug (6.2) & $9.8(5.3)$ & $73(30)$ & $2.2(4.0$ \\
\hline & & 2008 & 318 & 0.39 & 0.33 & 0.00 & 0.96 & 0.03 & 0.00 & $412.0(21.9)$ & $105.1(9.0)$ & $114.4(9.5)$ & 11 Aug (4.7) & $9.0(5.2)$ & & \\
\hline & & 2009 & 337 & 0.58 & 0.03 & 0.00 & 0.83 & 0.17 & 0.00 & $431.6(26.8)$ & $111.7(10.1)$ & $116.3(7.0)$ & 9 Aug (6.4) & $4.0(2.5)$ & & \\
\hline & \multirow{2}{*}{ M } & 2009 & 174 & 0.49 & 0.02 & 0.00 & 0.60 & 0.40 & 0.00 & $448.4(35.1)$ & $144.7(19.8)$ & $145.0(10.7)$ & 3 Aug (6.0) & $4.4(2.7)$ & & \\
\hline & & 2010 & 119 & 0.66 & 0.00 & 0.00 & 0.47 & 0.53 & 0.00 & 445 (33.2) & $138(18.7)$ & 139.7 (11.5) & 6 Aug (6.9) & $1.9(1.1)$ & & \\
\hline
\end{tabular}

Abbreviations: Bk, killed by brown bear; Ck, creek; F, female; M, male; PD, population density; RS, reproductive success; Sen, senescent; Std, standardized.

Data categories include spawning $\mathrm{Ck}$, sample size $(M)$, proportion of individuals that was killed by brown bears, numbers of individuals that were senescent, proportions of individuals in each age class based on otolith analyses and means for the following: body length in $\mathrm{mm}$ (Length), body depth in $\mathrm{mm}$ (Depth), standardized body depth in mm (Std depth), date of first entry into the stream (Date), reproductive lifespan (Lifespan, the number days observed in the stream), PD (mean number of live fish present in the stream each day) and RS (number of adult offspring produced per spawner). Standard deviations are listed below the means in parentheses.

inflation tests for multicollinearity showed that there was a high correlation (0.7) between death fate and reproductive lifespan; thus an interaction term between those factors was added to the full model. Owing to the lack of age data for most individuals, models did not include age, but length is highly correlated with age.

The regression models took the following form for the ith parent, with different traits $(X)$ denoted by different numeric subscripts:

$$
Y_{i}=\beta_{0}+X_{i 1} \beta_{1}+X_{i 2} \beta_{2}+X_{i 1} X_{i 2} \beta_{12}+\frac{\gamma_{1}}{2} X_{i 1}^{2}+\frac{\gamma_{2}}{2} X_{i 2}^{2}+\ldots+\varepsilon_{i}
$$

Here $Y$ is individual RS, $\beta$ is a linear selection gradient, $\gamma$ is a quadratic selection gradient and $\varepsilon_{i}$ is residual error. All regressions were run in the $\mathrm{R}$ package 'glmmADMB' (Skaug et al., 2011; R Development Core Team, 2013). We initially considered both linear and quadratic relationships between the response and continuous predictor variables. We then used tests based on AIC values to look for parsimonious models that fit the data well and had nonsignificant predictor variables removed. These were considered the final regression models.

\section{Quantitative genetic analysis}

We used quantitative genetic analyses to determine the potential for selection within each population. From the pedigree and the phenotypic data, genetic variance and covariance components for body length, standardized body depth, arrival date and reproductive lifespan were estimated for each population with a full-probability Bayesian animal model using the 'MCMCglmm' package (Hadfield, 2010) in R (R Development Core Team, 2013). For each phenotype, the model took the form:

$$
y_{i j k}=\mu+a_{i}+t_{j}+v_{k}+e_{i j k}
$$

where $y_{i j k}$ is a vector of phenotypes for phenotype $y$ in individual $i, \mu$ is the population mean phenotype, $a_{i}$ is the breeding value of individual $i$ (the random effect of interest: the contribution of $i$ to the distribution of $y$ relative to $\mu$, as estimated from the phenotypes of its relatives), $b_{j}$ is the fixed effect of brood year $j, s_{k}$ is the fixed effect of sex $k$ and $e_{i j k}$ is the residual term associated with $y_{i j k}$. Parameter-expanded inverse Wishart, inverse gamma or half-Cauchy priors were used to initiate each univariate and bivariate analysis. Genetic variances and covariances and their derivatives were estimated from the animal and residual effect estimates using single Markov chains 500 000-1 000000 iterations long, with $30000-50000$ burn-in iterations and thinning rates of 1 in 1000. Gelman-Rubin diagnostics and results of stationarity tests were inspected to ensure that effective sampling was high enough ( $>5000)$, lag autocorrelation low enough $(<0.01)$ and chain convergence sufficient for each analysis. The 95\% credible (highest posterior density) intervals for each estimate were obtained from the posterior densities.

\section{RESULTS}

\section{Demographic effects of bear predation}

Predation rates varied between brood years but not between populations; bears frequently fished both streams in 2004 but were rarely observed in 2005. Across sexes and streams, the average proportion of salmon killed by bears was $65 \%$ in 2004 but only $6.3 \%$ in 2005 (Table $1, P<0.001$ ). Bears did not appear to prefer either sex, as the proportions of bear-killed individuals did not differ significantly between sexes $(P>0.33)$. Salmon in both populations had shorter reproductive lifespans in 2004 than in $2005(P<0.001)$; consequently, the mean number of live fish present in the stream each day was lower in 2004 (Table 1; $P<0.001$ for A Creek, $P=0.047$ for C Creek), even though total population sizes were larger. Lifespan was always longer in C Creek than in A Creek, and that difference was most pronounced in 2004 (Table $1, P<0.01$ ). The mortality rate and reproductive lifespan estimates did not account for recapture uncertainty, but as described in the Materials and methods section, several measures were taken to avoid accidental resampling of individuals. In addition, recapture error would have to be quite large to appreciably influence the estimates.

Estimates of adult RPS in the A and C creek populations were lower for the 2004 brood year than the 2005 brood year, especially for the A 
Table 2 Numbers of spawning sockeye salmon adults per year and estimates of RPS for A Creek, C Creek and other Wood River system populations for the 2004 and 2005 brood years

\begin{tabular}{lrrrrrr}
\hline & $2004 \mathrm{~N}$ & $2005 \mathrm{~N}$ & $2008 \mathrm{~N}$ & $2009 \mathrm{~N}$ & $R^{2} P S_{2004}$ & $R^{20 S_{2005}}$ \\
\hline A & 550 & 461 & 238 & 644 & 0.4 & 1.4 \\
$\mathrm{C}$ & 460 & 306 & 490 & 511 & 1.1 & 1.7 \\
Eagle & 399 & 733 & 391 & 358 & 1.0 & 0.5 \\
Hansen & 3124 & 2909 & 2518 & 1136 & 0.8 & 0.4 \\
Mission & 643 & 479 & 770 & 40 & 1.2 & 0.1 \\
Elva & 185 & 192 & 253 & 222 & 1.4 & 1.2 \\
\hline
\end{tabular}

Abbreviation: RPS, recruits-per-spawner.

RPS $_{2004}$ is the number of spawning adults in 2008 (2008 N) divided by the number of spawning adults in $2004(2004 \mathrm{~N}$ ), and RPS 2005 is the number of spawning adults in 2009 (2009 N) divided by the number of spawning adults in 2005 (2005 N).

Creek population (Table 2). However, other Wood River system sockeye salmon populations showed the opposite pattern, with RPS estimates being greater for the 2004 than the 2005 brood year (Table 2). Fishery selectivity in the Nushagak district was very similar on age-4 (ocean age-3) sockeye salmon in 2008 and 2009 (1.13 and 1.20 , respectively; unpublished data), so fishery selectivity did not account for the difference in RPS between years.

Selection differentials indicated that bears tended to kill larger and more recently arrived fish in 2004, as the individuals that survived predation each day were smaller-bodied and had spent more time in the stream. The differentials were relatively consistent across sexes and populations, especially in cases where sample sizes (number of days and fish used in the analysis) were above 20 individuals (Table 3). In 2005, predation patterns on body size were less apparent in both populations, probably because of the very small number of bear kills that year (Table 3).

\section{Pedigree reconstruction}

All loci were significantly out of Hardy-Weinberg equilibrium in both populations, although $F_{\text {IS }}$ values were generally small $\left(F_{\mathrm{IS}}<0.05\right)$ except for One100 and One114 (Supplementary Table S1). There were also very high levels of linkage disequilibrium: of 55 pairwise tests between loci, 54 (98\%) were significantly out of linkage equilibrium $(P<0.05)$ in A Creek, as were $51(93 \%)$ in C Creek. Linkage disequilibrium was likely due to small population size rather than physical linkage between loci, As $N_{\mathrm{e}}$ values estimated from LDNE resulted in ratios of $N_{\mathrm{e}}$ to census sizes $\left(N_{e} / N=0.13-0.44\right)$ comparable to those reported for other salmonid populations (Waples, 2004). Averaged over all sampling years, $N_{\mathrm{e}}$ was 96 individuals for the A Creek population (95\% confidence interval, 78.9-116.6) and 88 individuals for the C Creek population (95\% confidence interval, 59.2-116.8). There was no indication of stuttering or large allele dropout according to MICROCHECKER analyses, and fewer than $2 \%$ of genotypes were missing from the data set. On average, there were 21.5 alleles per locus, with a mean expected heterozygosity of $H_{\mathrm{e}}=0.85$. The parentage exclusion probability over all loci was greater than 0.99 for both a single parent and for two parents.

Across both populations, $82 \%$ of adult offspring returning in 2008 and $96 \%$ of offspring returning in 2009 had at least one parent assigned (Supplementary Table S2). Only 33\% of offspring returning in 2010 had at least one parent assigned, but since most fish return as 4 -year olds, we sampled only some potential parents of this group. A total of 552 parent pairs were identified. Nearly all of these pairs were observed in the same stream (99\%) and the same year (95\%), suggesting $\sim 5 \%$ assignment error. 'Erroneous' pairings were defined
Table 3 Selection differentials for sockeye salmon body length in $\mathrm{mm}$ (Length), non-standardized body depth in $\mathrm{mm}$ (Depth) and reproductive lifespan in days (Lifespan)

\begin{tabular}{|c|c|c|c|c|c|c|c|}
\hline Trait & Year & Pop. & Sex & Diff. (mm or days) & StDiff. & Days & $\mathrm{N}$ \\
\hline Length & 2004 & A & $\mathrm{F}$ & -0.24 & -0.01 & 21 & 163 \\
\hline Length & 2004 & $A$ & $M$ & -3.76 & -0.12 & 10 & 76 \\
\hline Length & 2004 & $C$ & $\mathrm{~F}$ & -0.97 & -0.03 & 18 & 190 \\
\hline Length & 2004 & C & M & -1.03 & -0.03 & 10 & 77 \\
\hline Length & 2005 & $A$ & $\mathrm{~F}$ & 12.23 & 0.55 & 1 & 3 \\
\hline Length & 2005 & A & $M$ & -3.04 & -0.11 & 2 & 7 \\
\hline Length & 2005 & C & $\mathrm{F}$ & -3.93 & -0.20 & 4 & 12 \\
\hline Length & 2005 & $C$ & $M$ & -1.47 & -0.06 & 4 & 18 \\
\hline Depth & 2004 & A & $\mathrm{F}$ & -0.23 & -0.04 & 21 & 163 \\
\hline Depth & 2004 & A & $M$ & -3.76 & -0.12 & 10 & 76 \\
\hline Depth & 2004 & C & $\mathrm{F}$ & -0.30 & -0.04 & 18 & 190 \\
\hline Depth & 2004 & C & $\mathrm{M}$ & -0.25 & -0.03 & 10 & 77 \\
\hline Depth & 2005 & A & $\mathrm{F}$ & 0.95 & 0.21 & 1 & 3 \\
\hline Depth & 2005 & A & $M$ & -0.99 & -0.08 & 2 & 7 \\
\hline Depth & 2005 & C & $\mathrm{F}$ & 2.51 & 0.23 & 4 & 12 \\
\hline Depth & 2005 & C & $M$ & -0.33 & -0.04 & 4 & 18 \\
\hline Lifespan & 2004 & A & $\mathrm{F}$ & 0.18 & 0.23 & 21 & 163 \\
\hline Lifespan & 2004 & A & $M$ & 0.36 & 0.32 & 10 & 76 \\
\hline Lifespan & 2004 & C & $\mathrm{F}$ & 0.30 & 0.12 & 18 & 190 \\
\hline Lifespan & 2004 & C & $M$ & -0.13 & -0.01 & 10 & 77 \\
\hline Lifespan & 2005 & A & $\mathrm{F}$ & 0.95 & 0.31 & 1 & 3 \\
\hline Lifespan & 2005 & $A$ & $M$ & 0.52 & 0.11 & 2 & 7 \\
\hline Lifespan & 2005 & $C$ & $\mathrm{~F}$ & 0.38 & 0.14 & 4 & 12 \\
\hline Lifespan & 2005 & C & $M$ & -0.08 & -0.01 & 4 & 18 \\
\hline
\end{tabular}

Abbreviations: Diff., differential; F, female; M, male; Pop., population; StDiff, standardized differentials.

Diff. were calculated both as absolute and StDiff (Diff divided by the standard deviation) for each day that both bear-killed and live fish were present (Days = number of these days) and weighted by the harmonic mean of the numbers of bear-killed and live fish $(N$ - harmonic mean summed over all days).

as those where the parents were not observed in the same stream or same year. Selection analyses performed with and without the erroneous pairings showed the same patterns, and thus subsequent analyses were based on the data set that excluded these pairings.

\section{Selection coefficients}

Mean individual RS was lower in 2004 than in 2005 for both populations (A Creek: 0.85 in 2004 versus 3.08 in 2005, Mann-Whitney-Wilcoxon $W=74656, P<0.001$; C Creek: 2.30 in 2004 versus 2.65 in 2005, $W=50090, P=0.003$ ). RS varied substantially among individuals (standard deviations ranging from 1.6 to 7.7 ; Table 1), with many candidate parents producing no returning adult offspring ( $49 \%$ of males, $68 \%$ of females, Supplementary Figure S1). Within each population and brood year, females had lower mean RS than males ( $W$ ranging from 9527 to $21419, P<0.05$ ) because the overall sex ratio was female-biased (Table 1).

After testing regression models with and without death fate, we decided to focus on the models that excluded death fate (all model results shown in Supplementary Table S3). The models that included death fate identified few significant predictors because of the smaller sample sizes, and death fate was not a significant predictor of individual RS in any brood year or population despite consistent bear selectivity for larger and more recently arrived fish (Figure 2 and Table 3). In addition, the reproductive lifespan variable incorporated mortality from bear predation because bear-killed fish had shorter lifespans $(P<0.01$ according to Mann-Whitney-Wilcoxon tests). 


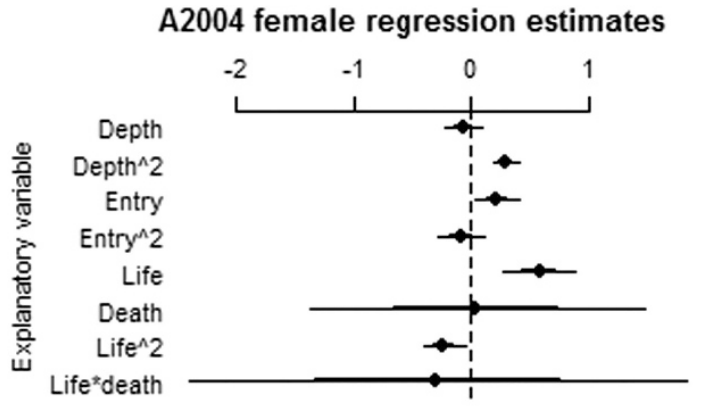

C2004 female regression estimates

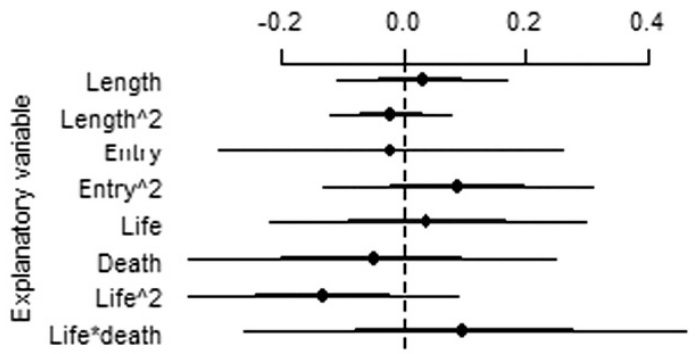

A2005 female regression estimates

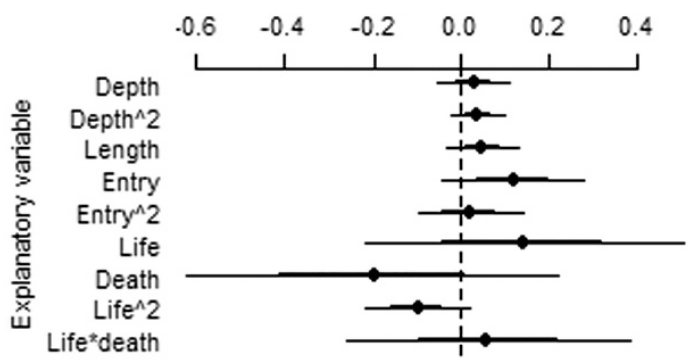

C2005 female regression estimates

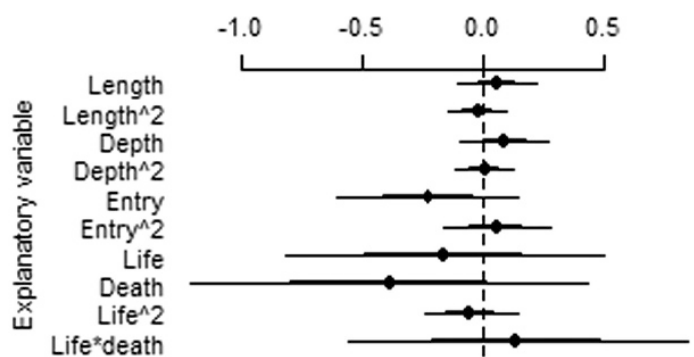

\section{A2004 male regression estimates}

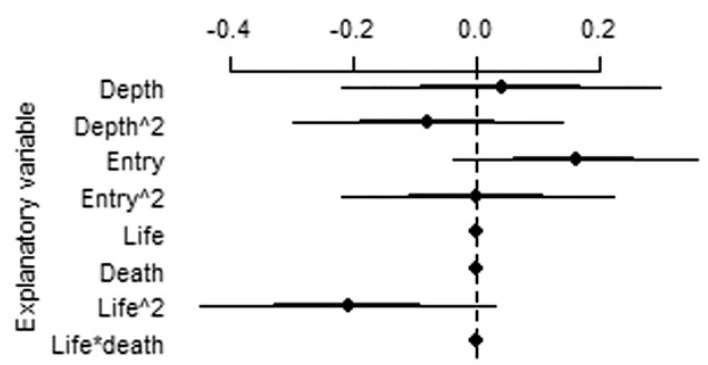

\section{C2004 male regression estimates}

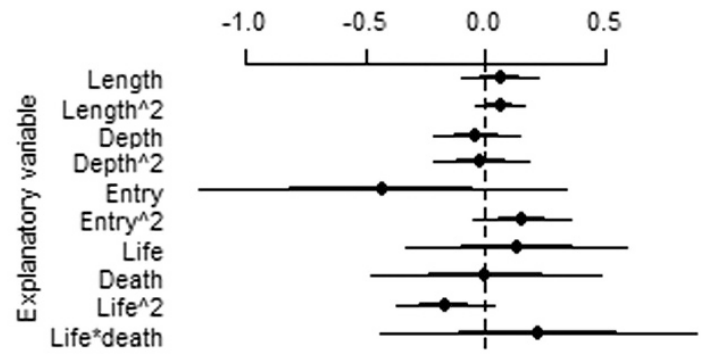

A2005 male regression estimates

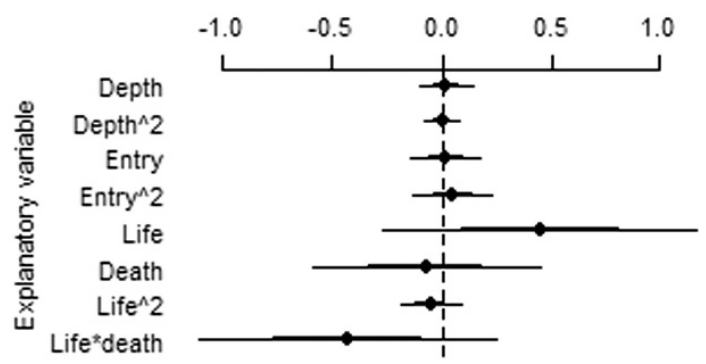

C2005 male regression estimates

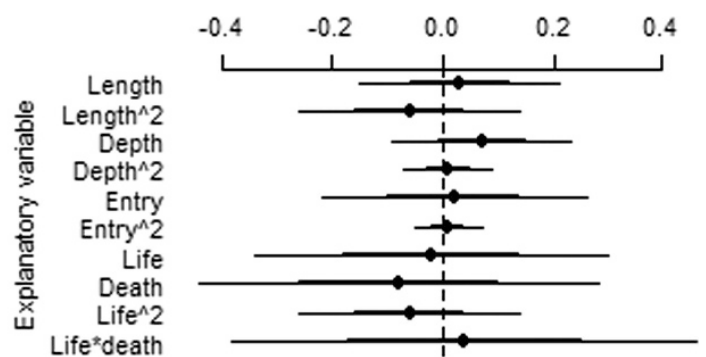

Figure 2 Regression results for the most parsimonious models that included death fate as a factor. Figures show estimates of selection coefficients (points), $95 \%$ confidence intervals (thin lines extending from the points) and $50 \%$ confidence intervals (thick lines extending from the points. Separate models were run for each brood year-sex-population combination. We used standardized rather than absolute body depth, which was highly correlated with body length. The $x$ axes represent the values of the selection coefficients. A2004 =A Creek 2004, C2004 =C Creek 2004, A2005=A Creek 2005, C2005 =C Creek 2005. For A Creek 2004 males, selection coefficient estimates for death fate and reproductive lifespan had extremely large standard errors (>100) and were not depicted here.

Estimated selection coefficients suggested directional selection for later stream entry date for both sexes in A Creek in 2004 and A Creek females in 2005, directional selection for longer reproductive lifespan for both sexes in A Creek in 2004 and 2005, and stabilizing selection on reproductive lifespan for both sexes in A Creek and for C Creek females in 2005 (Figure 3). There was no evidence for selection on adult body length or standardized body depth. There were no obvious differences in significant selection coefficients between the highpredation year (2004) and the low predation year (2005).
Quantitative genetic analysis

The genetic variance-covariance $(G)$ matrices estimated from the animal model analyses across years revealed broadly concordant patterns of phenotypic and genetic variation in body morphology and phenology in A and C creek sockeye salmon, but with notable differences involving reproductive lifespan (Figure 4, full estimates and confidence limits in Supplementary Table S4). In particular, detectable phenotypic and genetic variability were evident in both populations for body length and depth (as well as standardized depth; Supplementary 
A2004 female regression estimates

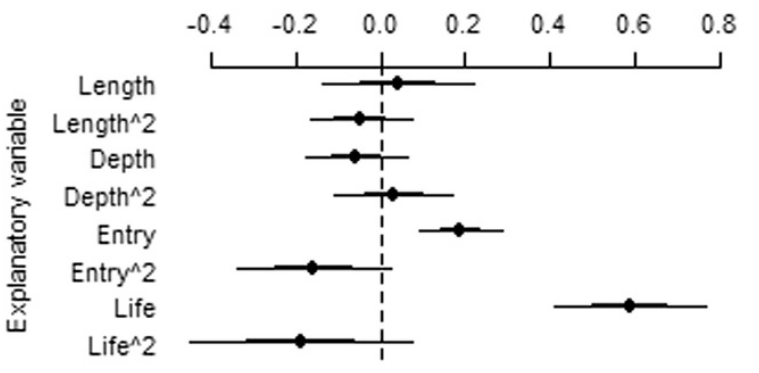

C2004 female regression estimates

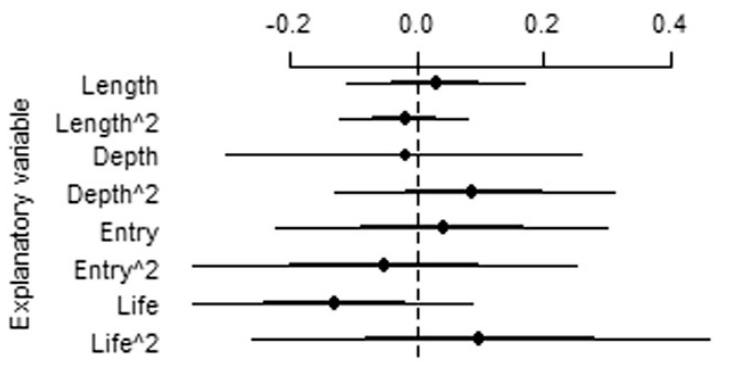

A2005 female regression estimates

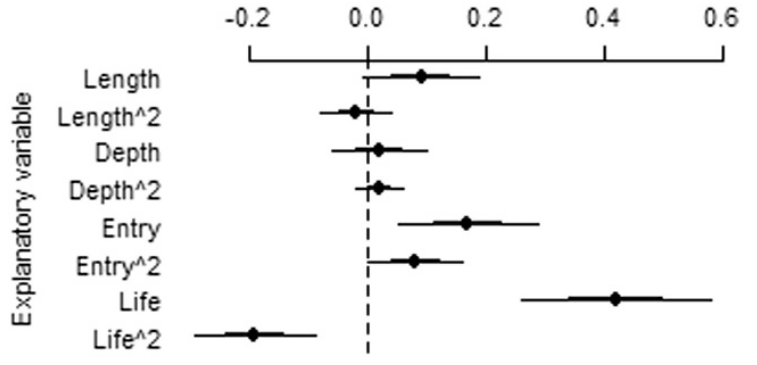

C2005 female regression estimates

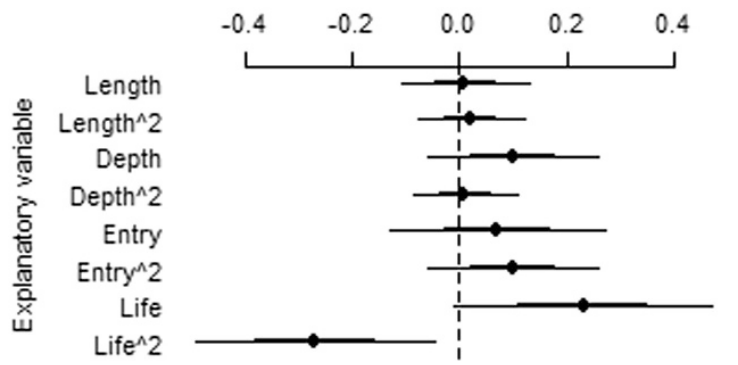

A2004 male regression estimates

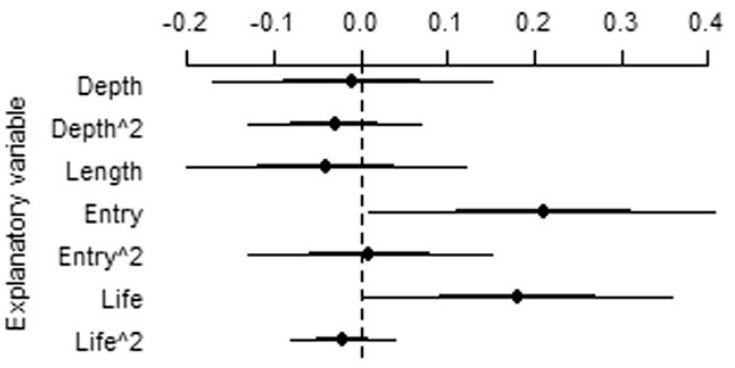

\section{C2004 male regression estimates}

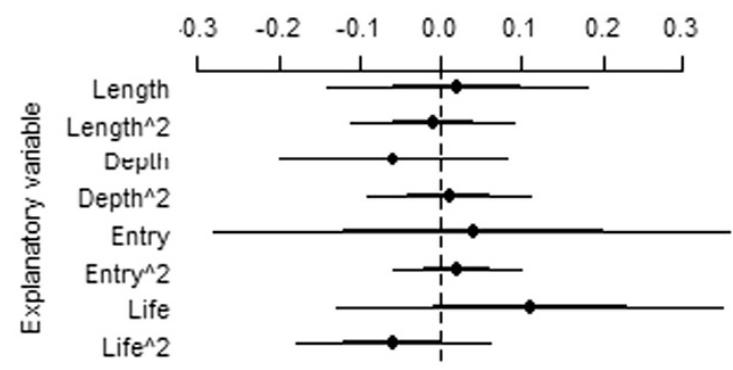

A2005 male regression estimates

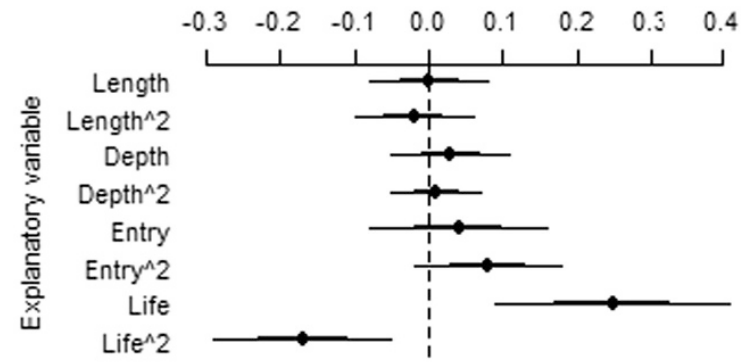

C2005 male regression estimates

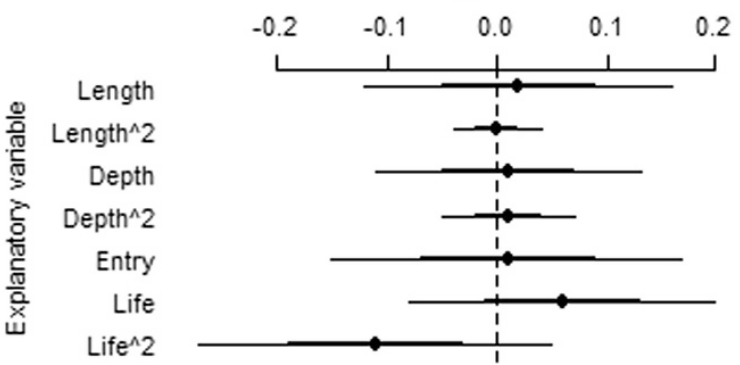

Figure 3 Regression results for models for the most parsimonious models that did not include death fate as a factor. Figures show estimates of selection coefficients (points), 95\% confidence intervals (thin lines extending from the points) and 50\% confidence intervals (thick lines extending from the points). Separate models were run for each brood year-sex-population combination. We used standardized rather than absolute body depth, which was highly correlated with body length. The $x$ axes represent the values of the selection coefficients. A2004 = A Creek 2004, C2004 =C Creek 2004, A2005=A Creek 2005, C2005 = C Creek 2005.

Table S4) and, especially, stream entry date; reproductive lifespan showed appreciable genetic variability in C Creek but not in A Creek fish. In both populations, genetic and phenotypic covariances suggested that individual body length and depth were highly positively correlated, and larger fish entered the streams earlier. In A Creek, larger fish had longer lifespans, but these traits were genetically uncorrelated; in C Creek, larger fish had shorter lifespans, and the genetic relationship between these traits was consistent in direction with the phenotypic correlation but larger. Finally, fish that entered A
Creek earlier had longer lifespans, a pattern that was also evident genetically, but in $\mathrm{C}$ Creek this pattern was considerably weaker (Figure 4).

Standardized body depth was correlated phenotypically with only reproductive lifespan in A Creek, but these traits were genetically uncorrelated in that population (Supplementary Table S4). Standardized depth and stream entry date were uncorrelated phenotypically in A Creek, but their genetic correlation was significantly negative, indicating that selection against relatively deep-bodied fish would 


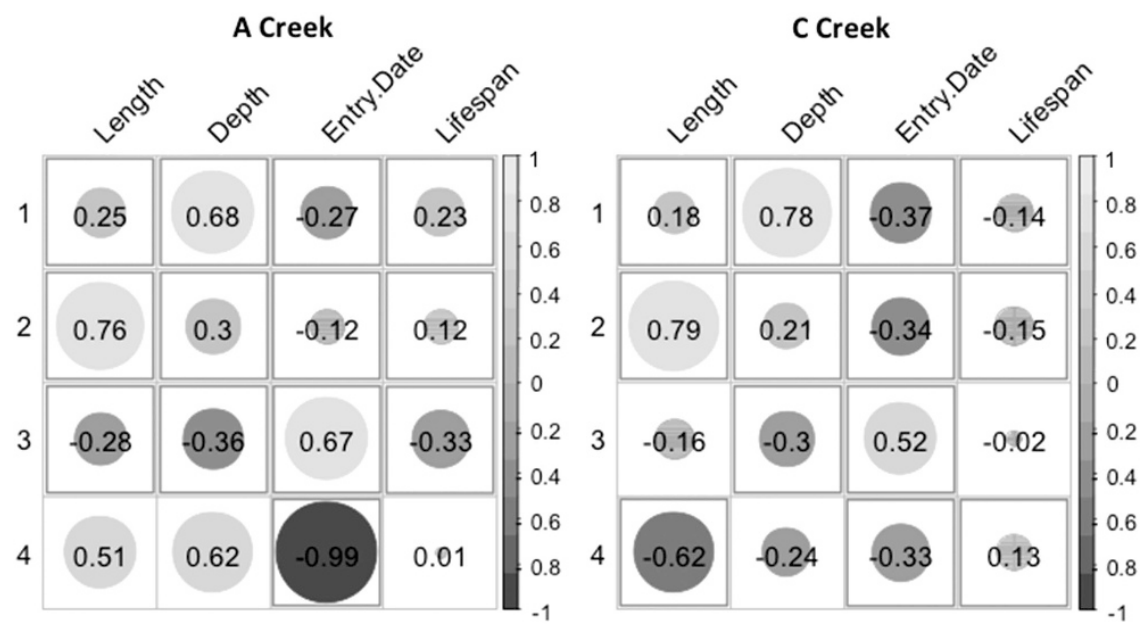

Figure 4 Scaled variance-covariance $(G)$ matrices for body length, body depth, stream entry date and reproductive lifespan of sockeye salmon in A and C creeks. Estimates in each circle (which scales in diameter with the absolute value of the estimate) are from full-probability Bayesian models conditioned on sex and brood year as fixed factors. In each matrix, narrow-sense heritabilities $\left(h^{2}\right)$ are given along the diagonal; phenotypic correlations $\left(r_{p}\right)$ are given above and genetic correlations $\left(r_{A}\right)$ below the diagonal. Heritabilities scale higher with lighter color; positive correlations $(r>0)$, lighter circles; negative correlations $(r<0)$, darker circles. Matrix cells with a dark gray outline indicate estimates whose $95 \%$ credible intervals do not include 0 . Matrices that include standardized depth and provide the estimates and 95\% credible intervals for all measured traits are given in Supplementary Table S4.

tend to favor fish entering earlier. In C Creek, standardized depth was uncorrelated phenotypically with length, entry timing or lifespan, but it was negatively genetically correlated with entry timing and positively genetically correlated with lifespan, indicating that selection against relatively deep-bodied fish would tend to favor earlier adult entry timing and longer lifespan (Supplementary Table S4).

Overall, the $G$ matrix for A Creek sockeye salmon indicated substantial genetic variation in body morphology and stream entry timing but not reproductive lifespan. However, negative genetic covariance between lifespan and entry timing suggested a tendency for selection against early adults to delay entry timing and reduce lifespan and body size of surviving spawners. The C Creek G matrix indicated somewhat lower genetic variation for morphology and phenology but higher variation for lifespan, and it suggested a tendency for selection against larger fish to increase lifespan and delay the stream entry date of surviving spawners (Figure 3). Such responses may only be detectable in years when selection differentials and effects on RS are large.

\section{DISCUSSION}

Previous studies of the effects of bear predation on sockeye salmon have reached several broad conclusions. First, bears can have substantial demographic effects on wild salmon populations, especially in shallow streams, and they often prefer to kill larger adults (Quinn and Kinnison, 1999; Quinn et al., 2001a), typically males (Gard, 1971). Second, bears often (but not always) prefer less senescent adults that have more recently arrived on the spawning grounds, especially in smaller streams where fish are easily caught (Hendry et al., 2004; Carlson et al., 2007). These patterns have led some to hypothesize that bear predation can accelerate senescence by imposing selection against early arrivals (Gende et al., 2004; Carlson et al., 2007). Third, selection differentials are distinct among populations in streams with differing habitat characteristics or spawner densities (Gende et al., 2004; Carlson et al., 2009; Cunningham et al., 2013), with predation tending to be more selective in streams where prey are more easily caught. Finally, the reproductive potential of wild sockeye salmon in pristine spawning habitat is generally very high, and high levels of bear predation may not substantially depress population productivity
(Quinn et al., 2014), although the selective effects of such predation appear to increase at low density (Cunningham et al., 2013).

In this study, we have, for the first time, directly quantified the evolutionary outcomes of bear predation. By reconstructing molecular pedigrees in two wild populations of sockeye salmon for two brood years that experienced differing levels of predation, we were able to both quantify the effects of bear predation on lifetime RS and estimate the genetic architecture of body morphology, entry timing and reproductive lifespan under selection. The combined analysis of selection coefficients and the quantitative genetic basis of trait variation provided insights into the likely evolutionary consequences of bear predation. Our results indicated that bears affected salmon demography by reducing mean individual RS, which was significantly higher in the 2005 brood year (lower predation) than the 2004 brood year in both the A and C creek populations. On the other hand, variation in the magnitude of bear predation did not substantially change selection coefficients in the two populations: although there was limited selectivity by bears for larger adults that had more recently entered the spawning stream, selection coefficients varied only slightly between years with different predation rates. Evidence for stabilizing and directional selection on reproductive lifespan and directional selection for later stream entry was observed for some sex-populationbrood year groups (Figure 3). Differences in predation intensity did not substantially alter the direction or magnitude of selection coefficients on body size between brood years in either population.

The most striking result was that mean individual RS was higher for the 2005 than the 2004 brood year for both populations, especially in the A Creek population, where mean RS almost tripled for both sexes (Table 1). This productivity difference could have resulted from bear predation as well as other factors such as quality of rearing habitat, harvest, ocean conditions and density dependence (for example, see Zabel et al., 2006). We could not quantify differences in the rearing lake habitat between brood years but considered the effects of ocean conditions by comparing productivities of the $\mathrm{A}$ and $\mathrm{C}$ creek populations to those of four other sockeye salmon populations in the Wood River system that did not sustain such extreme variation in predation rates between 2004 and 2005. All four populations produced 
more RPS in 2004 than 2005, contrary to the patterns observed in A and $\mathrm{C}$ creeks (Table 2). Thus, ocean conditions are an unlikely cause for the greater productivity of the 2005 brood year in the A and C creek populations.

Density dependence on the spawning grounds was another potential explanation for fitness differences between brood years. In the absence of mitigating factors, individual RS should decline with increasing population density because of increased competition for redd sites and mates (Foote, 1989). However, although total run sizes were smaller for the brood year with higher individual RS (2005), daily spawning densities were lower in 2004 because lifespans were shorter. Thus, differences in RS between brood years were probably not due to density-dependent effects in the stream.

The lower RS in 2004 was likely due to the higher predation rates that year. Bears typically kill salmon before they complete spawning and hence limit their reproductive opportunities (Carlson et al., 2009). Indeed, the average lifespan in A Creek was only 2.4 days for both sexes in 2004, less than a third of the 2005 average. In addition, the fitness difference between brood years was more pronounced in the A Creek population, which had the larger discrepancy in the proportion of bear-killed salmon between brood years (Table 1). Our results are consistent with the idea that bear predation can limit a cohort's productivity, although this effect might not drive adult recruitment below replacement (Quinn et al., 2014).

Estimates of selection differentials between bear-killed and senescent salmon were generally consistent with those from prior studies, although our selection differentials (Table 3) were slightly smaller. Quinn and Kinnison (1999) examined carcasses in spawning ponds near Pedro Bay, Alaska, and found that bear-killed salmon were $\sim 10 \mathrm{~mm}$ longer in body length than senescent salmon, and Quinn et al. (2001a) estimated that bear-killed fish were $0.1-28.5 \mathrm{~mm}$ longer in a Wood River system stream with intense bear predation (Hansen Creek). Cunningham et al. (2013) calculated standardized body length differentials in terms of standard deviation (s.d.) units for Hansen Creek sockeye salmon, and their differentials varied from about -0.6 to 0 . For samples including at least 20 individuals, our 2004 selection differentials showed consistent patterns, with absolute differentials ranging from $-3.76 \mathrm{~mm}$ to $-0.24 \mathrm{~mm}$, and the standardized differentials ranging from -0.20 to -0.12 s.d. (Table 3 ). The relatively small selection differentials in the A and $\mathrm{C}$ creek populations may have been partly due to the extreme environment of these shallow streams, where essentially all salmon are exposed to bear predation, and predation rates can be very high.

We detected some significant selection coefficients, most notably both directional selection for longer reproductive lifespan and stabilizing selection on lifespan (Figure 3), indicating that individuals with shorter reproductive lifespan had lower fitness than those with longer lifespan, but that individuals with lifespans near the population mean had the highest fitness. Successful reproduction likely requires some minimum duration of spawning for redd construction and defense in females and for mating opportunities in males (Hendry et al., 2004). On the other hand, an exceptionally long reproductive lifespan may not confer an additional fitness advantage. Previous research has found that females release their eggs more quickly in populations that experience high levels of predation (Clark, 1959), and individuals of both sexes that spawn quickly are more likely to produce offspring when there is a substantial risk of being killed. Hence, salmon in these populations may spawn rapidly, but spending at least some minimum time on the spawning grounds may improve RS. There was also indication of directional selection for later stream entry date in A Creek salmon (Figure 3), potentially because females that spawned later were subjected to less redd superimposition by other females and consequently lost fewer eggs (Hendry et al., 2004). No significant selection coefficients on body size were detected, possibly because different agents of selection have opposing effects on these traits. For example, larger body sizes may be advantageous in terms of sexual selection, whereas bear predation and harvest selection may favor smaller body sizes because larger fish are more likely to be killed (Quinn et al., 2001b; Kendall and Quinn, 2009).

Another consideration is that residual demographic and selective effects from previous years may have affected the selection coefficients we estimated. We could not account for these effects directly but note that stream entry date was the trait with the greatest opportunity for residual effects to be observed, based on the relatively high levels of genetic variability. However, there was no clear variation in mean stream entry date among the years in which we collected data (Table 1). Thus, although selective effects from previous years could have affected our observations, these effects may not have been strong.

Selection coefficients estimated previously for adult Pacific salmon have found directional and stabilizing selection on body size (Carlson et al., 2009; Kodama et al., 2012) and directional selection on arrival date to the spawning grounds (Anderson et al., 2010), although modes of selection were often not consistent annually. The selection coefficients estimated here were within the range of estimates obtained in a study of wild coho salmon that also used ZINB regression models, and our sample sizes per brood year and population were of a similar order of magnitude (Kodama et al., 2012).

Three factors may account for the lack of clear differences in selection coefficients between brood years that experienced differing levels of bear predation. First, predation was extremely sporadic: on some days, especially in 2004, almost every fish in the creeks was killed, whereas on others no bear predation was observed. Although bear selection differentials were weighted by the daily harmonic mean of bear killed and surviving fish, this sporadic predation likely reduced selectivity, which in turn reduced overall selection coefficients. Second, both streams are extremely shallow, making all salmon easily accessible to bears, and the high density of salmon in both creeks may also reduce bear selectivity (Cunningham et al., 2013). Finally, the small population sizes in both creeks enhance stochastic effects such as sporadic predation events, thereby limiting the deterministic effects of selection. In general, selective effects are more pronounced in larger populations (Frankham et al., 1968). Unfortunately, exhaustive pedigree studies such as the one conducted here are often not feasible in these larger populations.

The quantitative genetic analyses of the four traits examined in A and $\mathrm{C}$ creek sockeye salmon indicated that most of the traits express detectable amounts of genetic variation. In both populations, heritabilities were highest for entry date, modest for morphological traits and lowest for reproductive lifespan, especially in A Creek. Within each population, patterns of genetic and phenotypic covariation among traits were remarkably consistent, with genetic and phenotypic correlations among each pair of traits typically of the same sign (Figure 4). In most cases, the genetic correlations exceeded the phenotypic correlations in magnitude. However, there were some notable differences between the two populations. In particular, lifespan was genetically uncorrelated with morphology in A Creek (although the point estimates were positive) but negatively genetically correlated with body length in C Creek. Lifespan was negatively genetically correlated with entry date in both populations, but the magnitude of the correlation was considerably larger for A Creek fish (Figure 4). Thus, fish that enter A Creek earlier tend to live longer. In C Creek, this relationship is weaker, but those that do live longer tend to be 
smaller, a pattern that was not observed for A Creek fish. Together with the selection analyses, the $G$ matrices suggest that selection against early returning adults in A Creek would tend to reduce lifespans and body sizes of surviving spawners, whereas in C Creek selection against early returning adults would tend to increase body sizes and reduce lifespans of surviving spawners (Figure 4).

Estimating fitness in quantitative genetic analyses of phenotypes under selection provides a means of determining the targets of selection and potential constraints on evolution, and ascertaining whether important adaptations have been identified (Walsh and Blows, 2009). Our results suggest that key adaptations of spawning sockeye salmon involve both senescence and phenology. For reproductive lifespan, the combination of directional and stabilizing selection with relatively low genetic variability (Figures 3 and 4) suggests that reproductive lifespan is likely to be an important component of fitness that has responded to past selection in A and C Creek sockeye salmon but is unlikely to respond rapidly to current selection regimes. Directional selection for later stream entry was observed for both brood years of A Creek females (Figure 3). Relatively high variability in phenology may be maintained in both populations by fluctuating direct selection on this trait and correlational selection on reproductive lifespan (Figure 4).

In conclusion, this study demonstrated considerable demographic effects of bear predation but weaker evolutionary effects. Mean individual RS, but not selection coefficients, differed substantially between two years with very different predation regimes and spawner densities. In addition, despite preference of bears for killing larger and earlier spawners, genetic covariation between morphology, phenology and lifespan appears to have maintained variation in spawner body size and stream entry timing in both populations. Our study demonstrates how joint consideration of selection coefficients, selection differentials and quantitative genetic variability can provide insights into past and future effects of selection on wild populations.

\section{DATA ARCHIVING}

The phenotypic and microsatellite data used for pedigree reconstruction are stored on Dryad under DOI: 10.5061/dryad.b46qg.

\section{CONFLICT OF INTEREST}

The authors declare no conflict of interest.

\section{ACKNOWLEDGEMENTS}

Anne Hilborn, Ulrike Hilborn, Peter Westley, Allan Hicks, Daniel Schindler and Jackie Carter helped collect the field data, Melissa Baird provided genotypes, Curry Cunningham provided fishery selectivity data and Miyako Kodama assisted with the selection coefficient analysis. We also thank Tom Quinn for comments that helped improve the manuscript. Support was provided by the Institute for Ocean Conservation Science at Stony Brook University via a grant from the Pew Charitable Trusts, the Gordon and Betty Moore Foundation and the National Science Foundation (NSF grant \# OCE-0410437). Jocelyn Lin also received funding from an NSF Graduate Research Fellowship and a National Marine Fisheries Service/Sea Grant Joint Graduate Fellowship in Population Dynamics and Marine Resource Economics. The views expressed herein are those of the authors and do not necessarily reflect the views of NOAA or any of its sub-agencies.

Anderson J, Faulds P, Atlas W, Pess G, Quinn T (2010). Selection on breeding date and body size in colonizing coho salmon. Oncorhynchus kisutch. Mol Ecol 19: 2562-2573.

Beacham T, Margolis L, Nelson R (1998). A comparison of methods for stock identification for sockeye salmon (Oncorhynchus nerka) in Barkley Sound, British Columbia. North Pacific Anadromous Fish Comm Bull 1: 227-239.
Bentley K, Schindler D, Cline T, Armstrong J, Macias D, Ciepiela L, Hilborn R (2014). Predator avoidance during reproduction: diel movements by spawning sockeye salmon between stream and lake habitats. J Anim Ecol 83: 1478-1489.

Carlson S, Hilborn R, Hendry A, Quinn T (2007). Predation by bears drives senescence in natural populations of salmon. PLoS One 2: e1286.

Carlson S, Rich H, Quinn T (2009). Does variation in selection imposed by bears drive divergence among populations in the size and shape of sockeye salmon? Evolution 63: 1244-1261.

Clark W (1959). Kodiak bear-red salmon relationships at Karluk Lake, Alaska. Twentyfourth North Am Wildlife Conf 24: 337-345.

Coltman D, O'Donoghue P, Jorgenson J, Hogg J, Strobeck C, Festa-Bianchet M (2003). Undesirable evolutionary consequences of trophy hunting. Nature 426: 655-658.

Cunningham C, Hilborn R, Seeb J, Smith M, Branch T (2012). Reconstruction of Bristol Bay sockeye salmon returns using age and genetic composition of catch. University of Washington: Seattle, WA, USA.

Cunningham C, Ruggerone G, Quinn T (2013). Size selectivity of predation by brown bears depends on the density of their sockeye salmon prey. Am Nat 181: 663-673.

Dickerson B, Quinn T, Willson M (2002). Body size, arrival date, and reproductive success of pink salmon. Oncorhynchus gorbuscha. Ethol Ecol Evol 14: 29-44.

Endler J (1986). Natural Selection in the Wild. Princeton University Press: Princeton, NJ, USA

Foote C (1989). Female mate preference in Pacific salmon. Anim Behav 38: 721-723.

Frankham R, Jones L, Barker J (1968). The effects of population size and selection intensity in selection for a quantitative character in Drosophila: I. Short-term response to selection. Genet Res 12: 237-248.

Gard R (1971). Brown bear predation on sockeye salmon at Karluk Lake, Alaska. J Wildlife Manag 35: 193-204.

Gende S, Quinn T, Hilborn R, Hendry A, Dickerson B (2004). Brown bears selectively kill salmon with higher energy content but only in habitats that facilitate choice. Oikos 104: 518-528.

Hadfield JD (2010). MCMC methods for multi-response generalized linear mixed models: The MCMCgImm R package. J Stat Software 33: 1-22.

Hard J, Gross M, Heino M, Hilborn R, Kope R, Law R, Reynolds J (2008). Evolutionary consequences of fishing and their implications for salmon. Evol App/ 1: 388-408

Hauser L, Baird M, Hilborn R, Seeb L, Seeb J (2011). An empirical comparison of SNPS and microsatellites for parentage and kinship assignment in a wild sockeye salmon (Oncorhynchus nerka) population. Mol Ecol Resources 11: 150-161.

Hendry A, Morbey Y, Berg O, Wenburg J (2004). Adaptive variation in senescence: reproductive lifespan in a wild salmon population. Proc $R$ Soc Lond B Biol Sci 271: 259-266.

Hendry AP, Quinn TP (1997). Variation in adult life history and morphology among Lake Washington sockeye salmon (Oncorhynchus nerka) populations in relation to habitat features and ancestral affinities. Can J Fish Aquatic Sci 54: 75-84.

Hixon M, Carr M (1997). Synergistic predation, density dependence, and population regulation in marine fish. Science 277: 946-949.

Ihssen PE, Evans DO, Christie WJ, Reckahn JA, DesJardine RL. (1981). Life history, morphology, and electrophoretic characteristics of five allopatric stocks of lake whitefish (Coregonus clupeaformis) in the Great Lakes region. Can J Fish Aquatic Sci 38: 1790-1807.

Jones O, Wang J (2010). COLONY: a program for parentage and sibship inference from multilocus genotype data. Mol Ecol Resources 10: 551-555.

Kalinowski S, Taper M, Marshall T (2007). Revising how the computer program CERVUS accommodates genotyping error increases success in paternity assignment. $\mathrm{Mol}$ Ecol 16: 1099-1106.

Kendall N, Quinn T (2009). Effects of population-specific variation in age and length on fishery selection and exploitation rates of sockeye salmon (Oncorhynchus nerka). Can J Fish Aquatic Sci 66: 896-908.

Kendall N, Quinn T (2013). Size-selective fishing affects sex ratios and the opportunity for sexual selection in Alaskan sockeye salmon. Oikos 122: 411-420.

Kodama M, Hard J, Naish K (2012). Temporal variation in selection on body length and date of return in a wild population of coho salmon, Oncorhynchus kisutch. BMC Evol Biol 12: 116.

Lande R, Arnold S (1983). The measurement of selection on correlated characters. Evolution 37: 1210-1226.

Law R (2007). Fisheries-induced evolution: present status and future directions. Mar Ecol Progr Ser 335: 271-277

Lin J, Quinn TP, Hilborn R, Hauser L (2008). Fine-scale differentiation between sockeye salmon ecotypes and the effect of phenotype on straying. Heredity 101: 341-350.

Magnhagen C (1991). Predation risk as a cost of reproduction. Trends Ecol Evol 6: 183-185.

Mills L, Soule M, Doak D (1993). The keystone-species concept in ecology and conservation. Bioscience 43: 219-224.

Myers KW, Aydin KY, Walker RV, Fowler S, Dahlberg ML. (1996). North Pacific Anadromous Fish CommissionN. Pac. Anadr. Fish Comm. Doc. 192, FRI-UW- Vol. 192. University of Washington: Seattle, WA, USA, 228.

Nosil P, Crespi B (2006). Experimental evidence that predation promotes divergence in adaptive radiation. Proc Natl Acad Sci USA 103: 9090-9095.

Olsen JB, Wilson SL, Kretschmer EJ, Jones KC, Seeb JE (2000). Characterization of 14 tetranucleotide microsatellite loci derived from sockeye salmon. Mol Ecol 9: 2185-2187. 
Pemberton J (2008). Wild pedigrees: the way forward. Proc R Soc Lond B Biol Sci 275: 613-621.

Quinn T, Kinnison M (1999). Size-selective and sex-selective predation by brown bears on sockeye salmon. Oecologia 121: 273-282.

Quinn TP, Hendry AP, Buck GB (2001a). Balancing natural and sexual selection in sockeye salmon: interactions between body size, reproductive opportunity and vulnerability to predation by bears. Evol Ecol Res 3: 917-937.

Quinn TP, Wetzel L, Bishop S, Overberg K, Rogers DE (2001b). Influence of breeding habitat on bear predation and age at maturity and sexual dimorphism of sockeye salmon populations. Can J Zool 79: 1782-1793.

Quinn TP, Cunningham CJ, Randall J, Hilborn R (2014). Can intense predation by bears exert a depensatory effect on recruitment in a Pacific salmon population? Oecologia 176: 445-456.

R Development Core Team (2013). R: A Language and Environment For Statistical Computing. R Foundation for Statistical Computing: Vienna, Austria. ISBN 3-90005107-0, URL http://www.R-project.org/.

Raymond M, Rousset F (1995). Genepop (Version-1.2): population genetics software for exact tests and ecumenicism. J Heredity 86: 248-249.

Reznick D, Endler J (1982). The impact of predation on life-history evolution in Trinidadian guppies (Poecilia reticulata). Evolution 36: 160-177.

Reznick D, Rodd F, Cardenas M (1996). Life-history evolution in guppies (Poecilia reticulata: Poeciliidae) .4. Parallelism in life-history phenotypes. Am Nat 147: 319-338.
Seamons T, Bentzen P, Quinn T (2007). DNA parentage analysis reveals inter-annual variation in selection: results from 19 consecutive brood years in steelhead trout. Evol Ecol Res 9: 409-431.

Skaug H, Fournier D, Nielsen A (2011). glmmADMB: generalized linear mixed models using AD Model Builder. $R$ package version 0.7.

Vamosi S (2005). On the role of enemies in divergence and diversification of prey: a review and synthesis. Can J Zool 83: 894-910.

van Oosterhout D, Hutchison WF, Wills DPM, Shipley P (2004). MICROCHECKER: software for identifying and correcting genotyping errors in microsatellite data. Mol Ecol Notes 4: 535-538.

Walling C, Pemberton J, Hadfield J, Kruuk L (2010). Comparing parentage inference software: reanalysis of a red deer pedigree. Mol Ecol 19: 1914-1928.

Walsh B, Blows MW (2009). Abundant genetic variation + strong selection = multivariate genetic constraints: a geometric view of adaptation. Annu Rev Ecol Evol Syst 40: 41-59.

Waples RS (2004). Salmonid insights into effective population size. In: Hendry AP, Sterns SC (eds), Evolution Illuminated: Salmon and Their Relatives. Oxford University Press: Oxford, UK, pp 295-314.

Waples RS, Do C (2008). LDNE: A program for estimating effective population size from data on linkage disequilibrium. Mol Ecol Resources 8: 753-756.

Zabel R, Scheuerell M, McClure M, Williams J (2006). The interplay between climate variability and density dependence in the population viability of Chinook salmon. Conserv Biol 20: 190-200.

Supplementary Information accompanies this paper on Heredity website (http://www.nature.com/hdy) 